\title{
Anion Recognition as a Supramolecular Switch of Cell Internalization
}

Jéssica Rodríguez, ${ }^{\dagger}$ Jesús Mosquera, ${ }^{\dagger,}$ José R. Couceiro, ${ }^{\dagger}$ Jonathan R. Nitschke, ${ }^{*}+\bullet$ M. Eugenio Vázquez, ${ }^{\dagger}$ and José L. Mascareñas, ${ }^{*} \oplus \bullet$

${ }^{\dagger}$ Centro Singular de Investigación en Química Biolóxica e Materiais Moleculares (CIQUS) and Departamento de Química Orgánica, Universidade de Santiago de Compostela, 15782 Santiago de Compostela, Spain

${ }^{\star}$ Department of Chemistry, The University of Cambridge, Lensfield Road, Cambridge CB2 1EW, United Kingdom

\section{Supporting Information}

ABSTRACT: The cell internalization of designed oligoarginine peptides equipped with six glutamic acid residues and an anionic pyranine at the $\mathrm{N}$-terminus is triggered upon addition of a supramolecular host. This host binds specifically to the pyranine moiety, enabling the complex to traverse the cell membrane. Interestingly, none of the components, neither the host nor the guest, are able to cross the cell membrane on their own.

$\mathrm{R}$ ecent years have witnessed increased interest in the development of efficient cell-penetrating molecular transporters. ${ }^{1}$ Among the different strategies so far developed, those based on oligoarginine peptides are particularly effective, ${ }^{2,3}$ and have led to many biological and biomedical applications. ${ }^{4}$ An appealing step forward in this field would be the development of responsive systems whose cell internalization could be controlled using an external stimulus. Progress in this direction has been slow, and essentially limited to the temporary covalent attachment of negatively charged tails to the oligoarginine sequence through cleavable linkers. The polyanionic domain neutralizes the polycationic character of the peptide, thereby impairing its internalization; however the active cell penetrating peptide (CPP) is released upon application of a suitable external trigger, such as hydrogen peroxide, ${ }^{5} \mathrm{UV}$ light, ${ }^{6}$ or certain tumorassociated proteases. ${ }^{7}$ Although this strategy has raised expectations due to its potential biomedical applications, ${ }^{8}$ relying on the cleavage of a covalent linker limits the efficiency of the release, the selectivity of the process, and the reversibility of the switch. Furthermore, it inevitably leads to the generation of secondary polyanionic peptides that might have undesired effects. In this context, the development of stimuli-responsive cell internalization strategies that do not rely on covalent bond-cleavage reactions represents an appealing goal.

Anion recognition has been a topic of recent attention due to the essential functions of anions in biological systems. ${ }^{9}$ Metal organic self-assembly ${ }^{10}$ has allowed the generation of many new anion receptors. ${ }^{11}$ The application of these structures to biological systems is limited due to the toxicity of the metals and the instability of these species in the presence of competing ligands such as chloride or thiols in the intracellular medium. Alternatively, organic containers are ideal candidates due to their high stability and low toxicity. ${ }^{12}$ However, only a few covalent cages have been reported that are capable of encapsulating large anions in water with high affinity, and their biological applications are unknown. ${ }^{13}$

Herein we present a novel approach to control the cell uptake of oligoarginine CPPs based on the formation of a host-guest supramolecular complex involving an anion recognition process. The strategy relies on the encapsulation of a negatively charged pyranine attached to the $\mathrm{N}$-terminus of a peptide containing an octaarginine CPP. Interestingly, none of the components, the encapsulating host or the pyranine-peptide guest, are able to cross cell membranes in meaningful amounts as separate units, but their association promotes an efficient cellular uptake of both partners.

This approach was inspired by our recent discovery that the oligocationic covalent cage $\mathbf{1}$ (Figure 1) can selectively encapsulate the dye pyranine (pyr) with nanomolar affinity $\left(K_{\mathrm{D}} \approx 1.2 \mathrm{nM}\right) .{ }^{14}$ Considering that such an interaction might counterbalance the negative charges of the pyranine fluorophore, we envisioned that it could compensate the presumable transport

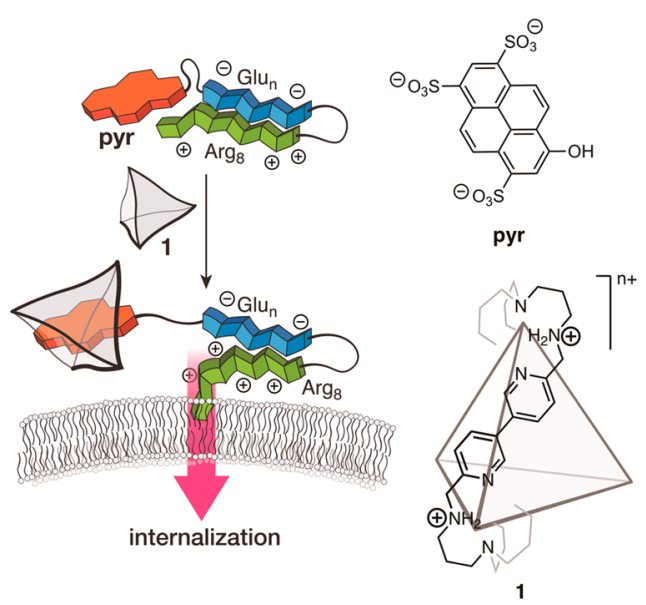

Figure 1. (Left) Concept of the switching strategy: an $\operatorname{Arg}_{8}$ CPP electrostatically masked by a polyanionic pyranine-Glu $\mathrm{n}_{\mathrm{n}}$ domain is activated by the formation of a supramolecular host-guest complex between the pyranine and a positively charged polyamine cage (1). (Right) Structures of pyranine (pyr), and the host cage 1 , in which six $N^{1}, N^{1}$ - ([3,3'-bipyridine $]-6,6^{\prime}$-diylbis(methylene))bis(propane-1,3-diamine) edges, sharing the terminal $N^{3}$ amines at the vertices, form a tetrahedral cage. Only one edge of the tetrahedron cage is shown for clarity.

Received: October 25, 2016

Published: December 16, 2016 
inhibitory effect of a pyranine-oligoglutamic oligoanion introduced at the $\mathrm{N}$-terminus of an octaarginine CPP.

As illustrated in Figure 1, pyr-Glu ${ }_{n}-\mathrm{Arg}_{8}$ peptides might not cross membranes; however, addition of the cage 1 was hypothesized to encapsulate the pyranine moiety, partly compensating the negative charges of the inhibitory $\mathrm{Glu}_{n}$ linker and thereby generating a transport-active complex. ${ }^{15}$

As shown in Scheme 1, the designed peptide shuttles (pyr$\mathbf{E}_{\mathbf{n}} \mathbf{R}_{\mathbf{8}}$ ) contain a oligoanionic domain connected to an

Scheme 1. Synthesis of Representative Peptide Derivatives Used in This Study, And Structure of the Control Peptide pyr$\mathbf{R}_{8}{ }^{a}$

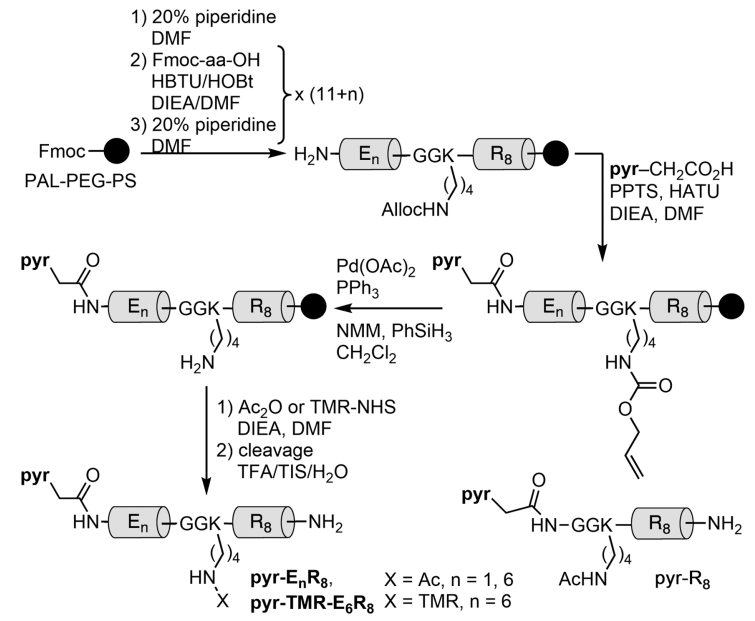

${ }^{a}$ See the Supporting Information. TMR $=5$-carboxytetramethylrhodamine.

octaarginine CPP through a short and flexible Gly-Gly-Lys spacer. The anionic pyranine fluorophore (pyr) is attached to the $\mathrm{N}$-terminus of the composite peptide sequences using a carboxylate derivative (pyr- $\mathrm{CH}_{2} \mathrm{CO}_{2} \mathrm{H}$ ).

The peptide conjugates were assembled following standard Fmoc solid phase peptide synthesis protocols, ${ }^{16}$ and the Lys residue in the spacer was incorporated with its side chain protected with an orthogonally cleavable Alloc group, so that it could be selectively removed in the solid phase to introduce various functionalities, ${ }^{17}$ such as the tetramethylrhodamine (TMR) fluorophore (Scheme 1).

In addition to shuttles with 1 and 6 glutamic acids, we also synthesized control peptides lacking Glu residues (pyr- $\mathbf{R}_{\mathbf{8}}$ ), as well as a $\mathbf{p y r}-\mathrm{E}_{\mathbf{6}} \mathbf{R}_{\mathbf{8}}$ derivative containing the TMR fluorophore attached to the Lys side chain (pyr-TMR- $\mathbf{E}_{\mathbf{6}} \mathbf{R}_{\mathbf{8}}$ ). The desired peptides were purified and characterized by LC-MS, and obtained in reasonable yields ranging from 15 to $30 \%$ (see the Supporting Information for details).

Having the desired compounds in hand, we analyzed their cell internalization properties in mammalian Vero cells by taking advantage of the intrinsic emission properties of the pyranine dye. Thus, although pyranine (pyr) is not capable of crossing the cell membrane by itself (Figure 2, left), its modification with an octaarginine CPP yields a conjugate $\left(\mathbf{p y r}-\mathbf{R}_{\mathbf{8}}\right)$ that is efficiently internalized in Vero cells upon incubation at $5 \mu \mathrm{M}$ concentration (Figure 2, right).

As hypothesized, the presence of only one glutamic acid in the oligoarginine conjugate ( $\mathbf{p y r}-\mathrm{E}_{\mathbf{1}} \mathbf{R}_{\mathbf{8}}$ ), led to a significant decrease in the cellular uptake (Figure 3, left). However, although pyr$\mathbf{E}_{1} \mathbf{R}_{8}$ was still partially taken up by cells, the introduction of six
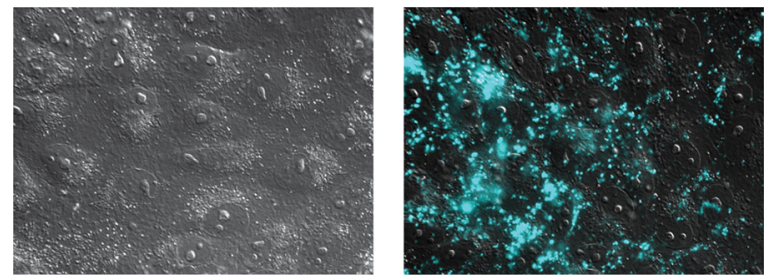

Figure 2. Fluorescence micrographies of Vero cells after incubation with $5 \mu \mathrm{M}$ of pyranine (pyr, left), or pyr- $\mathbf{R}_{\mathbf{8}}$ (right) in PBS, for 30 min at 37 ${ }^{\circ} \mathrm{C}$, followed by double washing with PBS, pH 7.5.
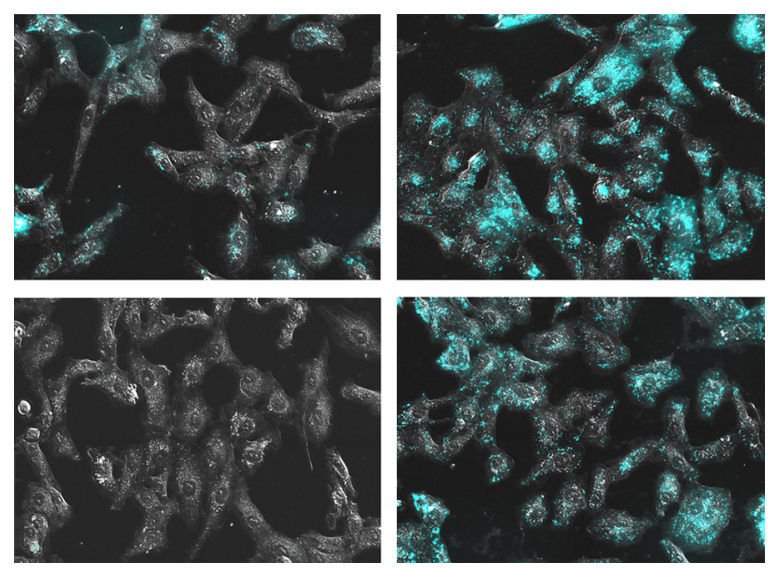

Figure 3. Fluorescence micrographies of Vero cells after incubation with $5 \mu \mathrm{M}$ of the pyranine conjugates in the absence (left) or presence (right) of 1 equiv of cage 1 , after $30 \mathrm{~min}$ at $37^{\circ} \mathrm{C}$, and after washing twice with PBS, pH 7.5. (Top) pyr- $\mathbf{E}_{1} \mathbf{R}_{8}$. (Bottom) pyr- $\mathbf{E}_{6} \mathbf{R}_{8}$.

glutamic acid residues led to a complete inhibition of the internalization, as can be deduced from the lack of significant intracellular emission for the conjugate $\mathbf{p y r}-\mathbf{E}_{\mathbf{6}} \mathbf{R}_{\mathbf{8}}$ (Figure 3, bottom left). Importantly, addition of 1 equiv of the supramolecular cage 1 to $\mathbf{p y r}-\mathrm{E}_{6} \mathbf{R}_{\mathbf{8}}\left(5 \mu \mathrm{M}, 30 \mathrm{~min}\right.$ at $\left.37{ }^{\circ} \mathrm{C}\right)$, led to a clear intracellular emission of the pyranine dye, which displays a similar endosomal localization to that observed for $\mathbf{p y r}-\mathbf{R}_{\mathbf{8}}$ (Figure 3, right). These results are in agreement with the proposed hypothesis that the encapsulation of the pyranine by the positively charged cage $\mathbf{1}$ leads to a supramolecular assembly with similar transport properties to those of $\mathbf{p y r}-\mathbf{R}_{\mathbf{8}}$. Quantifying the fluorescence at different times confirmed that the internalization rates increase upon addition of the cage to both pyr- $\mathbf{E}_{\mathbf{1}} \mathbf{R}_{\mathbf{8}}$ or pyr-E $\mathbf{E}_{\mathbf{6}} \mathbf{R}_{\mathbf{8}}$ (Figure S25).

Considering that previous fluorescence titrations of pyranine with the cage 1 showed that the pyranine emission is strongly quenched upon complexation, ${ }^{14}$ the above results suggest that the supramolecular complex may disassemble upon internalization. In any case, the cellular imaging results are consistent with the proposed model, in which the encapsulation of the pyranine fluorophore by positively charged cage 1 triggers the translocation of the supramolecular assembly. Importantly, cell viability assays confirmed that all peptides as well as cage $\mathbf{1}$ are essentially noncytotoxic (Figure S27).

In agreement with previous studies of the host-guest interaction between the cage $\mathbf{1}$ and the pyranine moiety, a fluorescence titration of a PBS solution of pyr- $\mathbf{E}_{\mathbf{6}} \mathbf{R}_{\mathbf{8}}(1 \mu \mathrm{M}, \mathrm{pH}$ 7.5) with increasing concentration of cage 1 produces a series of spectra of decreasing emission intensity due to the quenching of the pyranine fluorophore by the cage (Figure 4, left). Fitting of the titration curve to a $1: 1$ binding model (Figure 4, right), ${ }^{18}$ 

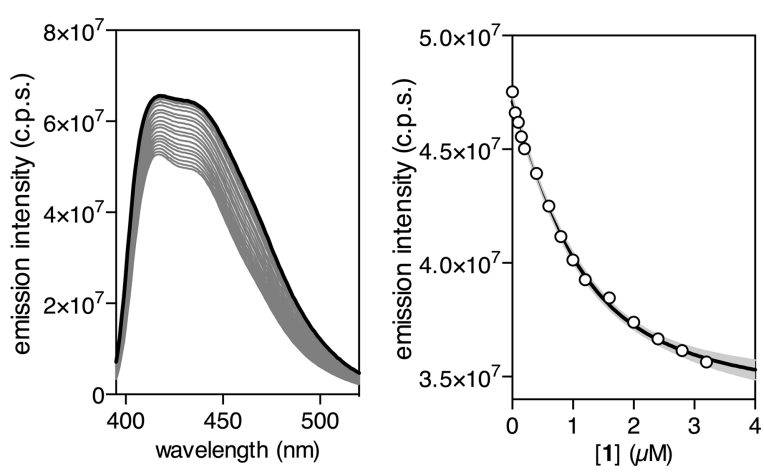

Figure 4. (Left) Fluorescence emission of $\mathbf{p y r}-\mathrm{E}_{6} \mathbf{R}_{8}$ (thick solid line) with increasing concentration of cage 1 in PBS buffer $\mathrm{pH} 7.5, \lambda$ exc $=380$ $\mathrm{nm}$ (gray lines). (Right) Emission profile with the best fit to a 1:1 model. 95\% Confidence interval plotted in gray.

allowed to obtain a $K_{\mathrm{D}}$ of approximately $278 \mathrm{nM}, 2$ orders of magnitude weaker than that observed for the complex $1 /$ pyr $\left(K_{\mathrm{D}}\right.$ $=1.2 \mathrm{nM}){ }^{14}$ This lower affinity might be beneficial in terms of favoring reversible encapsulations and the disassembly of the supramolecular complex after internalization, albeit this conclusion must be taken with caution owing to the complexity of the cellular environment.

Although the fluorescence of the pyranine allowed the preliminary analysis of the cell entrance capability of its CPP hybrids, the relatively low intensity of its blue emission advised the incorporation of a secondary probe with better emission properties (i.e., brighter, and fluorescent at longer wavelengths). Therefore, we explored the performance of the 5-carboxytetramethylrhodamine derivative pyr-TMR-E $\mathbf{E}_{\mathbf{6}} \mathbf{R}_{\mathbf{8}}$, which was synthesized as shown in Scheme 1.

Gratifyingly, although pyr-TMR-E $\mathbf{E}_{\mathbf{6}} \mathbf{R}_{\mathbf{8}}$ doesn't internalize, as deduced from the lack of intracellular fluorescence, addition of the cage 1 promoted a bright red intracellular fluorescence, emission that was mainly localized in endosomes (Figure 5, top). This observation is again consistent with an efficient uptake of the peptide in the presence of the supramolecular cage. Importantly, the switching can be reproduced in other types of
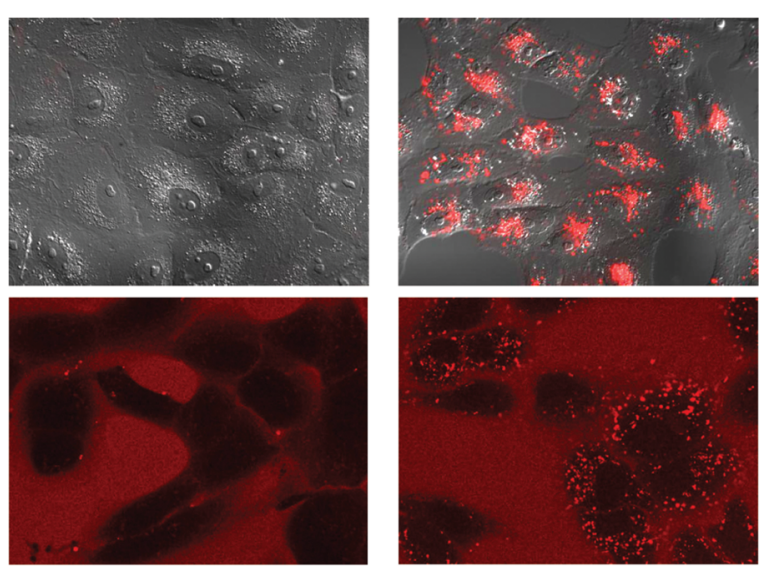

Figure 5. (Top) Fluorescence micrographies of Vero cells after incubation with $5 \mu \mathrm{M}$ pyr-TMR- $\mathrm{E}_{6} \mathbf{R}_{8}$ in the absence (left) or presence (right) of 1 equiv of cage 1 , incubations for $30 \mathrm{~min}$ at $37^{\circ} \mathrm{C}$, and after washing twice with PBS, $\mathrm{pH}$ 7.5. (Bottom) Confocal micrographies of Vero cells after incubation with $5 \mu \mathrm{M}$ pyr-TMR- $\mathbf{E}_{6} \mathbf{R}_{\mathbf{8}}$ in the absence (left) or presence (right) of 1 equiv of cage 1 , for $30 \mathrm{~min}$ at $37^{\circ} \mathrm{C}$, without washing.

cells, including A549 human lung carcinoma cells and HeLa, which provided similar results (Figure S23).

On the other hand, a more detailed analysis using confocal microscopy and avoiding washing steps, clearly showed that, in the absence of the cage, the red emission of the TMR was located outside of the cells. However, addition of 1 equiv of the host 1 led to the formation of red fluorescent vesicles inside cells $30 \mathrm{~min}$ after the addition (Figure 5, bottom).

To understand better the role of cage $\mathbf{1}$ in the cellular translocation of the complex, we also prepared a 5-carboxytetramethylrhodamine derivative of the cage, TMR-1, demonstrating that it is possible to carry out a modification of the initial cage (Figure 6, top). ${ }^{19}$ Interestingly, the TMR-modified cage (TMR-
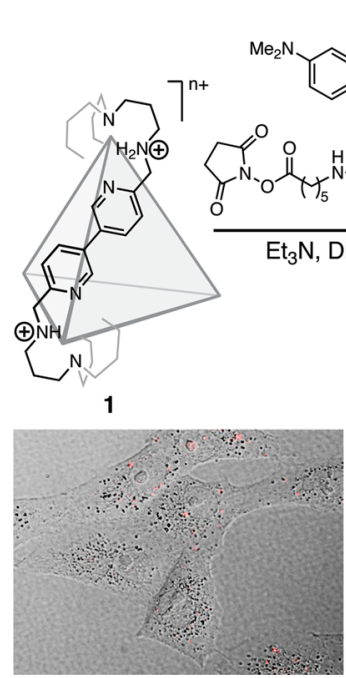

Figure 6. (Top) Synthesis of TMR-1. (Bottom) Fluorescence micrographies of Vero cells after incubation with $5 \mu \mathrm{M}$ TMR-1 in the absence (left) or presence (right) of 1 equiv of $\mathbf{p y r}-\mathbf{E}_{\mathbf{6}} \mathbf{R}_{\mathbf{8}}$, for $30 \mathrm{~min}$ at $37^{\circ} \mathrm{C}$ (double washing with $\mathrm{PBS}, \mathrm{pH} 7.5$ ).

1) showed a limited internalization into cells by itself. However, after the addition of pyr- $\mathbf{E}_{6} \mathbf{R}_{\mathbf{8}}$ to the medium, we observed the appearance of intracellular emission, consistent with the internalization of the TMR-1/pyr- $\mathbf{E}_{\mathbf{6}} \mathbf{R}_{\mathbf{8}}$ complex (Figure 6, bottom). In agreement with previous results, the emission was again mainly localized in endosomes, and fully colocalizes with that of the pyranine from the peptide shuttle (Figure S24). Therefore, the supramolecular host 1 not only triggers the activity of the octaarginine as a transporter, but can itself be also considered as a cargo. Therefore, this system represents an interesting case of supramolecular symbiosis, in which both partners, the host $\mathbf{1}$ and the $\mathbf{p y r}-\mathbf{E}_{\mathbf{6}} \mathbf{R}_{\mathbf{8}}$ guest, act synergistically to yield an efficient supramolecular transporter.

Finally, addition of an excess (over 3 equiv) of pyranine to the mixture of $\mathbf{1}$ and pyr- $\mathbf{E}_{\mathbf{6}} \mathbf{R}_{\mathbf{8}}$, before incubation with the cells, led to an almost complete inhibition of the cell internalization (Figure S26). This result further confirms that the cellular translocation is mediated by the proposed host-guest interaction.

In conclusion, we have demonstrated that organic supramolecular capsules can be used to regulate cellular uptake. The success of our strategy depends upon the cancellation of the cell membrane adhesiveness of an octaarginine transporter through introduction of an $\mathrm{N}$-terminal polyanionic tether formed by glutamic acids and an anionic pyranine. Addition of the supramolecular host relieves the quenching effect of the polyanion and triggers the cell entrance. This strategy, which 
involves an uncommon synergic supramolecular effect, might find important applications to control the spatial and temporal release of drugs, dyes or other agents inside cells. Furthermore, since both components, the cage and the peptide, can be covalently modified to attach molecules, this methodology might allow to internalize two different drugs at the same time.

\section{ASSOCIATED CONTENT}

\section{S Supporting Information}

The Supporting Information is available free of charge on the ACS Publications website at DOI: 10.1021 /jacs.6b11103.

Experimental details (PDF)

\section{AUTHOR INFORMATION}

\section{Corresponding Authors}

*J.M. joseluis.mascarenas@usc.es

*J.N.jrn34@cam.ac.uk

\section{ORCID ${ }^{\circ}$}

Jonathan R. Nitschke: 0000-0002-4060-5122

José L. Mascareñas: 0000-0002-7789-700X

\section{Author Contributions}

J.R. and J.M. contributed equally.

Notes

The authors declare no competing financial interest.

\section{ACKNOWLEDGMENTS}

We are thankful for the support given by the Spanish grants SAF2013-41943-R, CTQ2015-70698-R, and CTQ2013-49317EXP, the Consellería de Cultura, Educación e Ordenación Universitaria (GRC2013-041 and Centro singular de investigación de Galicia accreditation 2016-2019, ED431G/09), the European Regional Development Fund (ERDF), and the European Research Council (Advanced Grant No. 340055). Support of the orfeo-cinqa network (CTQ2014-51912-REDC) is kindly acknowledged. J.R. thanks the Xunta de Galicia for her Ph.D. fellowship, and J.M. thanks Fundación Ramón Areces for his postdoctoral fellowship. The authors thank R. Menaya-Vargas for technical assistance.

\section{REFERENCES}

(1) (a) Stanzl, E. G.; Trantow, B. M.; Vargas, J. R.; Wender, P. A. Acc. Chem. Res. 2013, 46, 2944. (b) Bartolami, E.; Bouillon, C.; Dumy, P.; Ulrich, S. Chem. Commun. 2016, 52, 4257. (c) Sgolastra, F.; Deronde, B. M.; Sarapas, J. M.; Som, A.; Tew, G. N. Acc. Chem. Res. 2013, 46, 2977. (d) Gasparini, G.; Bang, E.-K.; Montenegro, J.; Matile, S. Chem. Commun. 2015, 51, 10389.

(2) (a) Kauffman, W. B.; Fuselier, T.; He, J.; Wimley, W. C. Trends Biochem. Sci. 2015, 40, 749. (b) Bechara, C.; Sagan, S. FEBS Lett. 2013, 587, 1693. (c) Nakase, I.; Takeuchi, T.; Tanaka, G.; Futaki, S. Adv. Drug Delivery Rev. 2008, 60, 598.

(3) (a) Bolhassani, A. Biochim. Biophys. Acta, Rev. Cancer 2011, 1816, 232. (b) Milletti, F. Drug Discovery Today 2012, 17, 850. (c) Dubikovskaya, E. A.; Thorne, S. H.; Pillow, T. H.; Contag, C. H.; Wender, P. A. Proc. Natl. Acad. Sci. U. S. A. 2008, 105, 12128.

(4) (a) Madani, F.; Lindberg, S.; Langel, U.; Futaki, S.; Gräslund, A. J. Biophys. 2011, 2011, 414729. (b) Patel, L. N.; Zaro, J. L.; Shen, W. C. Pharm. Res. 2007, 24, 1977. (c) Jones, A. T.; Sayers, E. J. J. Controlled Release 2012, 161, 582. (d) Suzuki, T.; Futaki, S.; Niwa, M.; Tanaka, S.; Ueda, K.; Sugiura, Y. J. Biol. Chem. 2002, 277, 2437. (e) Kauffman, W. B.; Fuselier, T.; He, J.; Wimley, W. C. Trends Biochem. Sci. 2015, 40, 749. (f) Vázquez, O.; Blanco-Canosa, J. B.; Vázquez, M. E.; Martínez-Costas, J.; Castedo, L.; Mascareñas, J. L. ChemBioChem 2008, 9, 2822.
(5) Weinstain, R.; Savariar, E. N.; Felsen, C. N.; Tsien, R. Y. J. Am. Chem. Soc. 2014, 136, 874.

(6) (a) Penas, C.; Sánchez, M. I.; Guerra-Varela, J.; Sanchez, L.; Vázquez, M. E.; Mascareñas, J. L. ChemBioChem 2016, 17, 37. (b) Jiménez-Balsa, A.; Pazos, E.; Martínez-Albardonedo, B.; Mascareñas, J. L.; Vázquez, M. E. Angew. Chem., Int. Ed. 2012, 51, 8825.

(7) (a) Aguilera, T. A.; Olson, E. S.; Timmers, M. M.; Jiang, T.; Tsien, R. Y. Integr. Biol. 2009, 1, 371. (b) Olson, E. S.; Aguilera, T. A.; Jiang, T.; Ellies, L. G.; Nguyen, Q. T.; Wong, E. H.; Gross, L. A.; Tsien, R. Y. Integr. Biol. 2009, 1, 382. (c) Soo Hyeon Lee, S. H.; Moroz, E.; Castagner, B.; Leroux, J. C. J. Am. Chem. Soc. 2014, 136, 12868. (d) Goun, E. A.; Shinde, R.; Dehnert, K. W.; Adams-Bond, A.; Wender, P. A.; Contag, C. H.; Franc, B. L. Bioconjugate Chem. 2006, 17, 787.

(8) (a) Jiang, T.; Olson, E. S.; Nguyen, Q. T.; Roy, M.; Jennings, P. A.; Tsien, R. Y. Proc. Natl. Acad. Sci. U. S. A. 2004, 101, 17867. (b) Olson, E. S.; Jiang, T.; Aguilera, T. A.; Nguyen, Q. T.; Ellies, L. G.; Scadeng, M.; Tsien, R. Y. Proc. Natl. Acad. Sci. U. S. A. 2010, 107, 4311. (c) Nguyen, Q. T.; Olson, E. S.; Aguilera, T. A.; Jiang, T.; Scadeng, M.; Ellies, L. G.; Tsien, R. Y. Proc. Natl. Acad. Sci. U. S. A. 2010, 107, 4317.

(9) (a) Busschaert, N.; Caltagirone, C.; Van Rossom, W.; Gale, P. A. Chem. Rev. 2015, 115, 8038. (b) Custelcean, R. Chem. Soc. Rev. 2014, 43, 1813.

(10) (a) Black, S. P.; Wood, D. M.; Schwarz, F. B.; Ronson, T. K.; Holstein, J. J.; Stefankiewicz, A. R.; Schalley, C. A.; Sanders, J. K. M.; Nitschke, J. R. Chem. Sci. 2016, 7, 2614. (b) Howlader, P.; Mukherjee, P. S. Chem. Sci. 2016, 7, 5893. (c) Metherell, A. J.; Ward, M. D. Chem. Sci. 2016, 7, 910. (d) Otte, M.; Kuijpers, P. F.; Troeppner, O.; IvanovićBurmazović, I.; Reek, J. N. H.; de Bruin, B. Chem. - Eur. J. 2013, 19, 10170. (e) Wang, W.; Wang, Y.-X.; Yang, H.-B. Chem. Soc. Rev. 2016, 45, 2656. (f) Zarra, S.; Wood, D. M.; Roberts, D. A.; Nitschke, J. R. Chem. Soc. Rev. 2015, 44, 419.

(11) (a) Cook, T. R.; Stang, P. J. Chem. Rev. 2015, 115, 7001 (b) Löffler, S.; Lübben, J.; Krause, L.; Stalke, D.; Dittrich, B.; Clever, G. H. J. Am. Chem. Soc. 2015, 137, 1060. (c) Mosquera, J.; Zarra, S.; Nitschke, J. R. Angew. Chem., Int. Ed. 2014, 53, 1556. (d) Ramsay, W. J.; Rizzuto, F. J.; Ronson, T. K.; Caprice, K.; Nitschke, J. R. J. Am. Chem. Soc. 2016, 138, 7264.

(12) (a) Kang, S. O.; Llinares, J. M.; Day, V. W.; Bowman-James, K. Chem. Soc. Rev. 2010, 39, 3980. (b) Qiao, B.; Anderson, J. R.; Pink, M.; Flood, A. H. Chem. Commun. 2016, 52, 8683. (c) Tresca, B. W.; Hansen, R. J.; Chau, C. V.; Hay, B. P.; Zakharov, L. N.; Haley, M. M.; Johnson, D. W. J. Am. Chem. Soc. 2015, 137, 14959. (d) Zhang, G.; Mastalerz, M. Chem. Soc. Rev. 2014, 43, 1934.

(13) Langton, M. J.; Serpell, C. J.; Beer, P. D. Angew. Chem., Int. Ed. 2016, 55, 1974.

(14) (a) Mosquera, J.; Zarra, S.; Nitschke, J. R. Angew. Chem., Int. Ed. 2014, 53, 1556. (b) For a review, see: Busschaert, N.; Caltagirone, C.; Van Rossom, W.; Gale, P. A. Chem. Rev. 2015, 115, 8038.

(15) (a) Chuard, N.; Fujisawa, K.; Morelli, P.; Saarbach, J.; Winssinger, N.; Metrangolo, P.; Resnati, G.; Sakai, N.; Matile, S. J. Am. Chem. Soc. 2016, 138, 11264. (b) Takeuchi, T.; Kosuge, M.; Tadokoro, A.; Sugiura, Y.; Nishi, M.; Kawata, M.; Sakai, N.; Matile, S.; Futaki, S. ACS Chem. Biol. 2006, 1, 299. (c) Herce, H. D.; Garcia, A. E.; Cardoso, M. C. J. Am. Chem. Soc. 2014, 136, 17459.

(16) Coin, I.; Beyermann, M.; Bienert, M. Nat. Protoc. 2007, 2, 3247.

(17) (a) Rodríguez, J.; Mosquera, J.; García-Fandiño, R.; Vázquez, M. E.; Mascareñas, J. L. Chem.Sci. 2016, 7, 3298. (b) Rodríguez, J.; Mosquera, J.; Couceiro, J. R.; Vázquez, M. E.; Mascareñas, J. L. Chem. Sci. 2015, 6, 4767. (c) Vázquez, M. E.; Caamaño, A. M.; MartinezCostas, J.; Castedo, L.; Mascareñas, J. L. Angew. Chem., Int. Ed. 2001, 40, 4723.

(18) Kuzmič, P. In Methods in Enzymology; Spies, M.; Chemla, Y. R., Eds.; Academic Press, Elsevier, 2009; Vol. 467, p 247.

(19) (a) Chakrabarty, R; Stang, P. J. J. Am. Chem. Soc. 2012, 134, 14738. (b) Fuller, A.-M.; Leigh, D. A.; Lusby, P. J.; Oswald, I. D. H.; Parsons, S.; Walker, D. B. Angew. Chem., Int. Ed. 2004, 43, 3914. (c) Roberts, D. A.; Pilgrim, B. S.; Cooper, J. D.; Ronson, T. K.; Zarra, S.; Nitschke, J. R. J. Am. Chem. Soc. 2015, 137, 10068. 